\title{
Anabases
}

ANABASES Traditions et réceptions de l'Antiquité

$16 \mid 2012$

Varia

\section{Luke PITCHER, Writing Ancient History. An Introduction to Classical Historiography}

Pascal Payen

\section{OpenEdition}

Journals

Édition électronique

URL : http://journals.openedition.org/anabases/4037

DOI : 10.4000/anabases.4037

ISSN : 2256-9421

Éditeur

E.R.A.S.M.E.

Édition imprimée

Date de publication : 1 octobre 2012

Pagination : 323-325

ISSN : 1774-4296

Référence électronique

Pascal Payen, «Luke pitchen, Writing Ancient History. An Introduction to Classical Historiography »,

Anabases [En ligne], 16 | 2012, mis en ligne le 01 octobre 2012, consulté le 22 septembre 2020. URL:

http://journals.openedition.org/anabases/4037 ; DOI : https://doi.org/10.4000/anabases.4037

Ce document a été généré automatiquement le 22 septembre 2020.

(c) Anabases 


\section{Luke PITCHER, Writing Ancient History. An Introduction to Classical Historiography}

Pascal Payen

\section{RÉFÉRENCE}

Luke PITCHER, Writing Ancient History. An Introduction to Classical Historiography, London,

I.B.Tauris, 2009, 275 p. + ix p.

20 euros / isbn 978-1-84511-958-4.

1 Comment écrire l'histoire ancienne? Quelles sont les traditions disponibles, depuis qu'Hérodote, reconnu comme le "père de l'histoire " (pater historiae) par Cicéron, a utilisé le terme historiè (historia) dès les premiers mots de son œuvre avec le sens d' "enquête ", dans son déroulement même ? Les modernes peuvent-ils se considérer comme les héritiers en droite ligne des Anciens? Comment les historiens anciens se reconnaissent-ils entre eux? En quoi se différencient-ils de nous, et depuis quand, si césure il y a, celle-ci est-elle intervenue ? Ces questions du « comment » ne sont ellesmêmes jamais éloignées du " pourquoi » on écrit l'histoire. Le livre de Luke Pitcher les aborde toutes sans détour, sans jargon, avec clarté, à destination d'un public d'étudiants qui découvrent ces problèmes et qui disposent là d'un très utile instrument et d'une synthèse pour découvrir ce que l'on nomme désormais historiographie, c'est-àdire à la fois un champ d'étude: l'histoire de l'histoire, et un corpus d'œuvres: l'ensemble des historiens grecs et latins. L'historiographie n'est toutefois pas appréhendée pour elle-même; elle reste un outil pour écrire, si possible mieux, l'histoire. C'est pourquoi l'auteur ne part pas de définitions préétablies ou d'une méthode déduite de la pratique de Thucydide, sans que l'on sache ce qui nous autoriserait à généraliser dans l'espace et dans le temps et à dire ce que devraient être les règles de la méthode historique. 
2 Luke Pitcher préfère montrer que les historiens anciens sont l'objet, depuis une quarantaine d'années, dirons-nous, de deux modes d'approche, à peu près irréconciliables. D'un côté, les classiques de l'historiographie grecque et latine, d'Hérodote à Tite-Live et Plutarque, sont considérés comme des réservoirs de données et de faits vrais, dans lesquels l'historien moderne doit puiser pour légitimer son propre travail et, de surcroît, remplir ses notes infra-paginales. Selon l'autre perspective, ils sont étudiés comme des maîtres du récit, de sorte que la vérité qu'ils véhiculent ne réside plus dans les faits, mais dans l'architecture narrative, les modalités $\mathrm{du}$ discours et leurs propres manières d'administrer les preuves de ce qu'ils avancent. Chacun aura compris qu'il est aisé de mettre des noms derrière chacune de ces deux approches et que presque chaque historien ancien connaît des spécialistes de l'une et l'autre. Il est dommage que cette ligne directrice, tôt annoncée, n'ait pas été nettement suivie. Elle aurait donné sa pleine cohérence au livre. Pour tenter d'échapper à ce blocage entre deux lignes interprétatives et de réconcilier des écoles engagées dans des guerres de plus en plus picrocholines, les huit chapitres du livre s'appuient sur de nombreux textes, célèbres, empruntés aux historiens anciens. Afin de montrer quels sont les procédés propres aux Anciens destinés à rapporter les faits - par exemple sur le dossier des sources, la question de l'«autopsie »-, il aurait été utile d'y ajouter le problème de l'écriture, présent dès les premiers mots de Thucydide. En faisant ce choix, l'auteur ne joue pas les faits contre la narration, la vérité contre le soupçon, le «fond du problème " contre «le style, la forme et la composition ", l'histoire contre la littérature. Peut-être pourra-t-on considérer qu'en procédant de la sorte, Luke Pitcher met davantage en valeur les constantes de l'historiographie ancienne, plutôt que les évolutions. Mais on doit aussi reconnaître que, dès le IV ${ }^{\mathrm{e}}$ siècle avant J.-C., Hérodote et Thucydide sont reconnus comme des classiques, dont on prend la suite, et qu'il en est de même chez Lucien, admirateur de l'un et de l'autre, dans son Comment il faut écrire l'histoire (vers 165 ap. J.-C.), seul traité de ce type de l'Antiquité qui nous soit parvenu. Ce plaidoyer pour l'historiographie ancienne est aussi une défense très limpide de la nécessité plus générale de pratiquer l'historiographie. L'historien, débutant ou chevronné, ne peut éviter de se demander quelles sortes de données il recherche, comment il les collecte, quels mots il choisit pour dire le passé, comment il construit le résultat de son enquête. À ces questions les historiens anciens apportent tous des réponses, certes dans des termes qui ne sont plus les nôtres. Seule cette voie, parcourue avec rigueur, sans complaisance, peut conduire à se demander s'il existe des raisons d'écrire l'histoire ancienne.

3 L'ensemble repose sur une connaissance approfondie de la tradition de l'historiographie ancienne et des études d'historiographie moderne qui l'étudient. Les problèmes sont exposés avec clarté. Tous les lecteurs, et pas seulement le public des étudiants auxquels ce livre est explicitement destiné, y trouveront des bilans, des états de la question et des références, notamment dans les nombreuses notes. La bibliographie finale d'une vingtaine de pages reprend tous les classiques en langue anglaise de ce champ d'étude. On regrettera d'autant plus que, sur un tel sujet, les traditions italiennes, allemandes et françaises soient à peu près passées sous silence. Le tournant des années 1810, lorsque se met en place la "science de l'Antiquité » (Altertumswissenschaft), dans le cadre de l'université prussienne, aurait également mérité une attention. Thucydide quitte alors le domaine des Belles Lettres, pour devenir le modèle de l'historien scientifique épris de "la recherche de la vérité ", d'exactitude et d'impartialité, un Ancien au service des Modernes, pour construire 
l'histoire comme science, discipline et profession. Dans le même temps, George Grote écrit une histoire "libérale » imprégnée du présent et qui fait d'Athènes la nouvelle cité de référence, tandis que Droysen invente l'époque hellénistique, le temps des grands États unifiés dont rêvent pour eux-mêmes bien des Allemands. Il est dommage que ce moment crucial pour l'écriture de l'histoire ancienne n'ait pas trouvé place dans ce livre, car c'est toujours en fonction des choix qui furent retenus dans ces décennies que s'est construite l'histoire de l'Antiquité dont nous dépendons plus ou moins consciemment. De là l'utilité des études d'historiographie pour lesquelles ce livre fournit une utile introduction.

\section{AUTEURS}

\section{PASCAL PAYEN}

Université de Toulouse (UTM)

payen@univ-tlse2.fr 